\title{
An investigation on factors associated with malnutrition among underfive children in Nakaseke and Nakasongola districts, Uganda
}

\author{
Gilbert Habaasa
}

\begin{abstract}
Background: Malnutrition is one of the major causes of mortality and morbidity among under-five children in Sub Saharan Africa. To understand the factors associated with malnutrition among under-five children, a study was conducted in Nakaseke and Nakasongola districts of Uganda.

Method: Cross sectional secondary data of 104 underfive children in Nakaseke and Nakasongola districts was used. Epi Info programme-Nutrition module and Stata statistical softwares were used in analyses. Descriptive statistics, cross tabulations and binary logistic regression results were generated.

Result: Stunting was found to be the most malnutrition condition with the highest prevalence (38.5 \%) in the two districts followed by wasting (16.5\%) and underweight (13.5\%) respectively. Results also showed that children aged 39-59 months were less likely to be underweight than those aged below twelve months. Children of peasant farmers were more likely to be stunted than their counterparts with mothers in pastoralist's family. No significant factors were found to be associated with wasting among the underfive children in the two districts although the prevalence was slightly higher than that of child underweight.

Conclusion: The study is essential in pointing out the particular age-groups among underfive children as well as the maternal occupations that may be factors associated with malnutrition in the districts of Nakaseke and Nakasongola. The author recommends exclusive breast feeding and proper complementary feeding especially among children under three years. Furthermore, special arrangement could be put in place to have children of mothers engaged in cultivation brought to them regularly for breastfeeding.
\end{abstract}

Keywords: Breastfeeding, Pastoralism, Childcare, Strategies

\section{Background}

The World Health Organization in a recent report estimates that there are 178 million malnourished children across the globe, and at any given moment, 20 million of these are suffering from the most severe form of malnutrition. Malnutrition contributes between 3.5 and 5 million annual deaths among under-five children. UNICEF estimates about 195 million children suffering from malnutrition across the globe [1]. This consequently affects the intelligence level of children, their behaviour and school performance. The impaired mental development is taken as the most serious long-term handicap associated with underfive malnutrition. In Sub-Saharan Africa, $41 \%$ of

Correspondence: habaasa@hotmail.com

Population and Development Consult Limited, Kampala, Uganda under-five children are malnourished and deaths from malnutrition are increasing on daily basis in the region [2].

In Uganda, malnutrition remains a serious health and welfare problem affecting the under-five children to whom it contributes significantly to mortality and morbidity. According to Uganda Demographic and Health Survey of 2011, four in ten Ugandan children under-five years of age (33\%) are stunted (short for their age), six percent are wasted (thin for their height), and 14 percent are underweight (low weight for age) [3]. Indeed, these statistics may not be different from the districts of Nakaseke to Nakasongola in Uganda. Worthy to note is that the Ugandan government has put in place a number of initiatives aimed at reducing the prevalence of malnutrition in the country; The 2004/2005 Uganda food and 
nutrition policy reform, the Uganda Vision 2040 and 2010-2015 National Development Plan [4, 5].

Little improvement on underfive nutrition indicators in Uganda has been realized for the past 15 years [3]. Given the number of studies on malnutrition among underfive children in developing countries, there is need to examine if similar factors are associated with malnutrition among underfive children in Uganda particularly in the districts of Nakaseke and Nakasongola.

The specific study objectives were; (i) To ascertain the prevalence of malnutrition among underfive children, establish the relationship (ii) between demographic factors and malnutrition, (iii) between socio-economic factors and malnutrition among underfive children. The hypotheses tested were (i) There is no relationship between demographic factors and malnutrition among under-five children. (ii) There is no relationship between socio-economic factors and malnutrition among underfive children.

\section{Methods}

Cross sectional data of 104 underfive children (full sample) was obtained from Africa Innovations Institute (AfrII). Categorical data was collected in 2012 from households within the districts of Nakaseke and Nakasongola. The two districts were covered by the AfrII project "Adaptation to the impact of climatic variability on food and health security in the cattle corridor of Uganda" funded by International Development Research Centre (IDRC), Canada. Five public health experts from Makerere University School of public health were engaged in taking of anthropometry measurements for the underfive children. The full methodology and sampling procedures undertaken during data collection can be found elsewhere [6].

Child variables that included age, sex, height and weight were entered in Epi Info7 software-nutrition module to generate measurement indices of height-for-age, weightfor-age and weight-for-height. The indices generated were compared with standard reference values for CDC 2000 growth references to obtain the Z-scores. For this study, three indices of malnutrition that included stunting, underweight and wasting were determined among all the under-five children. Children whose height-for-age Zscore was below minus 2 standard deviation from the median of the reference population were classified as stunted. Children having weight-for-age Z-score less than minus 2 standard deviation from the median of the reference population were regarded as underweight. Similarly, all the children under-five years whose weight for height Zscores were less than minus 2 standard deviation were regarded as wasted [7].

The nutrition indicators of stunting, wasting and underweight were entered in stata programme and then merged with the demographic and socio-economic data for analysis. Descriptive statistics as well as cross tabulations were generated. Cross tabulations with Pearson Chi Square $\left(\chi^{2}\right)$ tests were performed to establish the association between under-five malnutrition with demographic and socioeconomic characteristics of the children. At multivariate analysis, a binary logistic regression model was fitted to ascertain the factors associated with malnutrition among children underfive years. The independent variables entered included; sex of child, age of child, birth order, birth interval, mother's age at birth, mother's education level, mother's marital status and mothers occupation. The dependent variables were stunting, underweight and wasting.

\section{Ethics}

Clearance was obtained from the Ethical board of Uganda National Council for Science and Technology to conduct the study. A written and signed informed consent was obtained from parents and guardians for the participation of their children in the study. Respondents were assured that the information would be used for intervention and academic purposes only. There were no blood samples taken from the respondents and the study did not pose any danger to them. The data collected did not have personal information like names and besides the variables were coded for confidentiality purpose.

The author also obtained the dataset and official permission from Africa Innovations Institute to undertake this study.

\section{Results}

\section{Background characteristics}

The background characteristics are divided into demographic and socio-economic factors as presented below.

\section{Demographic factors}

More than half of the under-five children in the study were females and majority were aged 37-59 months. Half of the children were of birth order 1-2 with a few in the birth order of 3-4 and 5+ order respectively. Most of the children were of birth intervals equal or less than two years. On the age of the mother at birth, majority of the children had their mothers aged 30-39 years while quite a significant proportion was also from children whose mothers at birth were aged 20-29 years. Few of the children were from mothers aged less than 20 years and 40-49 years at birth respectively. The details of the findings on the demographic factors among underfive children are presented in Table 1.

\section{Socio-economic factors}

Most of the mothers had received primary level education and quite a few had never been to school. Majority of the mothers were married or cohabiting. Most of the mothers were peasant farmers followed by those engaged in 
Table 1 Demographic factors of the underfive children

\begin{tabular}{lll}
\hline Demographic factors $(n=104)$ & Frequency & Percentage (\%) \\
\hline Sex of Child & 51 & 49 \\
Male & 53 & 51 \\
Female & & \\
Age of the child (months) & 76 & 73.1 \\
$\leq 12$ & 16 & 15.4 \\
$13-36$ & 12 & 11.5 \\
$37-59$ & & \\
Birth Order & 52 & 50 \\
$1-2$ & 26 & 25 \\
$3-4$ & 26 & 25 \\
$5+$ & & \\
Birth Interval (years) & 46 & 44.2 \\
$\leq 2$ & 43 & 41.3 \\
$3-4$ & 15 & 14.5 \\
$5-6$ & & 11.5 \\
Age of mother at birth (years) & 16 & 32.7 \\
$<20$ & 34 & 40.4 \\
$20-29$ & 42 & \\
$30-39$ & 12 & \\
$40-49$ & & \\
\hline
\end{tabular}

business, public service and pastoralism. Details are presented in Table 2.

\section{Levels of malnutrition among underfive children}

Results indicate that stunting was the most common malnutrition problem among underfive children in Nakaseke and Nakasongola district. There was also quite a high prevalence of wasting and underweight among underfive children given the fact that the sample size of children was not very big. On the levels of malnutrition by district;

Table 2 Socio-economic factors of the underfive children

\begin{tabular}{lll}
\hline Socio-economic factors $(n=104)$ & Frequency & Percentage (\%) \\
\hline Mothers' educational level & 16 & 15.4 \\
No education & 76 & 73.1 \\
Primary & 12 & 11.5 \\
Secondary+ & & \\
Marital status of the mother & 35 & 33.7 \\
$\quad$ Never Married/Separated & 69 & 66.3 \\
Married/Cohabiting & & \\
Mothers' Occupation & 52 & 50.0 \\
Peasant farmer & 14 & 13.4 \\
Pastoralist & 32 & 30.8 \\
Business/civil servant & 6 & 5.8 \\
Handcrafts & & \\
\hline
\end{tabular}

results indicate that Nakaseke district had a higher prevalence of stunting than Nakasongola. Similarly, Nakaseke had higher prevalence of child wasting and underweight respectively than Nakasongola district. The levels of malnutrition among children underfive years in Nakaseke and Nakasongola districts in Central Uganda are presented in Table 3.

\section{Relationship between demographic and socio-economic factors with malnutrition}

The study showed that slightly more females were stunted compared to the males. For wasting and underweight, xfemales were equally more wasted and underweight respectively than their male counterparts despite the fact that there was no significant relationship between sex of child and malnutrition.

On the age of a child, there was a significant relationship between age of child and underweight $\left(p=0.041^{* *}<0.05\right)$. There were few underweight children aged 13-59 months unlike those aged 12 months and below.

For birth order, stunting was highest among children of birth order 1-4 than those of order 5 and above. Children of birth order 3-4 were more wasted than those of birth order 1-2 or 5+. Similarly, underweight was highest among children of birth order 3-4.

On the birth interval, stunting was highest among underfive children with birth interval of 3-4 years.

Results also indicate that there were more stunted children among mothers aged 30-39 years than those aged 20-29 years or even $40-49$ years. There was however no significant relationship between age of mother at birth and stunting. However, there were more wasted children among mothers aged 20-29 years unlike other age groups. It is indicated that majority of underweight children were from mothers aged 40-49 years. There was no significant relationship between age of mother and malnutrition among underfive children.

For wasting, however, more children of birth interval $\leq 2$ years were wasted. On underweight, only few cases of children with birth interval 4 years and below were underweight. There was however no significant relationship between birth interval and all the malnutrition indices that is stunting, wasting and underweight.

There was no significant relationship between mother's education level and malnutrition indicators. The relationships of mother's education with stunting, wasting and

Table 3 Levels of malnutrition among underfive children

\begin{tabular}{lcll}
\hline Malnutrition Index & Overall status (\%) & $\begin{array}{l}\text { Nakaseke } \\
(n=54)\end{array}$ & $\begin{array}{l}\text { Nakasongola } \\
(n=50)\end{array}$ \\
\hline Stunting & 38.5 & $23(42.6 \%)$ & $17(34.0 \%)$ \\
Wasting & 16.5 & $12(22.2 \%)$ & $5(10.2 \%)$ \\
Underweight & 13.5 & $9(16.7)$ & $5(10.0 \%)$ \\
\hline
\end{tabular}


underweight were statistically insignificant since the pvalues were greater than 0.05 at $95 \%$ confidence interval.

On the marital status, majority of the stunted children were from mothers who were married or cohabiting. Similarly, there were more wasted and underweight children among married or cohabiting couples. There was however no significant relationship between marital status and malnutrition.

There was a significant relationship between mothers occupation and underfive child stunting $(p=0.05)$. More stunted children were from peasant farmers. In the same vein, wasting and underweight was common among peasant farmers and pastoralists. Results on the relationship between demographic and socio-economic factors with malnutrition indicators among underfive children are presented in Table 4.

\section{Factors associated with malnutrition among underfive children}

Results in Table 5 indicate that children aged 37-59 months were less likely to be underweight $(\mathrm{OR}=0.76)$ than their counterparts who were aged 12 months and below

Table 4 Bivariate associations between demographic and socio-economic factors with malnutrition among underfive children

\begin{tabular}{|c|c|c|c|c|c|c|c|c|c|c|}
\hline \multirow[t]{2}{*}{ Explanatory variable } & \multirow{2}{*}{$\begin{array}{l}\text { Total } \\
\text { children }\end{array}$} & \multicolumn{3}{|l|}{ Stunting } & \multicolumn{3}{|l|}{ Wasting } & \multicolumn{3}{|l|}{ Underweight } \\
\hline & & Stunted (\%) & $x^{2}$ & $p$ & Wasted (\%) & $x^{2}$ & $p$ & Underweight (\%) & $x^{2}$ & $p$ \\
\hline Sex of the child & & & 0.011 & 0.546 & & 3.302 & 0.069 & & 1.839 & 0.159 \\
\hline Male & 39 & $15(38.5)$ & & & $3(7.7)$ & & & $2(5.1)$ & & \\
\hline Female & 48 & 19(39.6) & & & $11(22.9)$ & & & $7(14.6)$ & & \\
\hline Age of child (months) & & & 1.992 & 0.737 & & 0.788 & 0.94 & & 9.952 & $0.041^{*}$ \\
\hline$\leq 12$ & 76 & $32(42.1)$ & & & $13(17.1)$ & & & $9(11.8)$ & & \\
\hline $13-36$ & 16 & $4(25)$ & & & $2(12.5)$ & & & 0 & & \\
\hline $37-59$ & 12 & $6(50)$ & & & $2(16.7)$ & & & $5(41.7)$ & & \\
\hline Birth Order & & & 0.438 & 0.803 & & 2.921 & 0.232 & & 5.378 & 0.068 \\
\hline $1-2$ & 43 & $19(44.2)$ & & & $3(6.9)$ & & & $3(6.9)$ & & \\
\hline $3-4$ & 18 & $8(44.4)$ & & & $4(22.2)$ & & & $4(22.2)$ & & \\
\hline $5+$ & 17 & $6(35.3)$ & & & $3(17.6)$ & & & 0 & & \\
\hline Birth Interval (years) & & & 5.085 & 0.079 & & 0.153 & 0.926 & & 0.795 & 0.672 \\
\hline$\leq 2$ & 38 & $15(39.5)$ & & & $6(15.7)$ & & & $4(10.5)$ & & \\
\hline $3-4$ & 17 & $11(64.7)$ & & & $2(11.8)$ & & & $2(11.8)$ & & \\
\hline $5-6$ & 6 & $1(16.7)$ & & & $1(16.7)$ & & & 0 & & \\
\hline Age of mother at birth (years) & & & 3.135 & 0.371 & & 1.351 & 0.717 & & 1.503 & 0.681 \\
\hline$<20$ Years & 16 & $6(37.5)$ & & & $2(12.5)$ & & & $2(12.5)$ & & \\
\hline 20-29 Years & 41 & 15 (36.6) & & & $7(17.1)$ & & & $3(7.3)$ & & \\
\hline 30-39 Years & 23 & $13(56.5)$ & & & $3(13.0)$ & & & $3(13.0)$ & & \\
\hline 40-49 Years & 7 & $2(28.6)$ & & & 0 & & & 0 & & \\
\hline Mother's education level & & & 1.135 & 0.769 & & 3.525 & 0.317 & & 2.866 & 0.413 \\
\hline No education & 11 & $3(27.3)$ & & & $3(27.3)$ & & & $2(18.2)$ & & \\
\hline Primary & 57 & $25(43.9)$ & & & $6(10.5)$ & & & $4(7.0)$ & & \\
\hline Secondary+ & 11 & $5(45.6)$ & & & $2(18.2)$ & & & 0 & & \\
\hline Marital Status & & & 1.331 & 0.275 & & 1.55 & 0.362 & & 0.032 & 0.584 \\
\hline Never married/Separated & 34 & $11(32.4)$ & & & $3(8.8)$ & & & $3(8.8)$ & & \\
\hline Married/Cohabiting & 56 & $25(44.6)$ & & & $11(19.6)$ & & & $6(10.7)$ & & \\
\hline Mothers' occupation & & & 11.03 & $0.05^{*}$ & & 3.101 & 0.684 & & 3.419 & 0.636 \\
\hline Peasant farmer & 44 & $20(45.5)$ & & & $6(13.6)$ & & & $5(11.4)$ & & \\
\hline Pastoralist & 11 & $1(9.1)$ & & & $2(18.2)$ & & & 0 & & \\
\hline Business/civil servant & 15 & $9(60)$ & & & $3(20)$ & & & 0 & & \\
\hline Handcraft & 6 & $2(27.3)$ & & & 0 & & & 0 & & \\
\hline
\end{tabular}

*Statistically significant at $95 \%$ Confidence Interval 
Table 5 Factors associated with malnutrition among underfive children in Nakaseke and Nakasongola districts

\begin{tabular}{|c|c|c|c|c|c|c|c|c|c|}
\hline \multirow[t]{2}{*}{ Variable } & \multicolumn{3}{|c|}{ Stunting } & \multicolumn{3}{|c|}{ Wasting } & \multicolumn{3}{|c|}{ Underweight } \\
\hline & $\mathrm{OR}$ & $\beta$ & $p$ & $\mathrm{OR}$ & $\beta$ & $p$ & $\mathrm{OR}$ & $\beta$ & $p$ \\
\hline \multicolumn{10}{|l|}{ Sex of the child (Male ${ }^{a}$ ) } \\
\hline Female & 1.07 & 0.48 & 0.89 & 3.36 & 2.34 & 0.08 & 2.98 & 2.48 & 0.19 \\
\hline \multicolumn{10}{|c|}{ Age of child ( $\leq 12^{\mathrm{a}}$ months) } \\
\hline 13-36 months & 0.38 & 0.26 & 0.16 & 0.79 & 0.65 & 0.78 & 0.67 & 0.59 & 0.65 \\
\hline $37-59$ months & 0.76 & 0.46 & 0.66 & 0.79 & 0.65 & 0.78 & 4.14 & 2.74 & $0.03^{*}$ \\
\hline \multicolumn{10}{|l|}{ Birth Order $\left(1-2^{\mathrm{a}}\right)$} \\
\hline $3-4$ & 0.74 & 0.42 & 0.59 & 3.62 & 2.98 & 0.12 & 3.62 & 2.99 & 0.12 \\
\hline $5+$ & 0.69 & 0.42 & 0.55 & 2.92 & 2.56 & 0.22 & 4.40 & 5.78 & 0.26 \\
\hline \multicolumn{10}{|l|}{ Birth Interval ( $\leq 2^{a}$ years) } \\
\hline $3-4$ years & 2.33 & 1.44 & 0.17 & 0.71 & 0.63 & 0.70 & 1.14 & 1.05 & 0.88 \\
\hline $5-6$ years & 1.86 & 2.18 & 0.59 & 0.72 & 0.66 & 0.72 & 1.04 & 0.84 & 0.96 \\
\hline \multicolumn{10}{|c|}{ Age of mother at birth $\left(<20\right.$ Years $\left.^{\mathrm{a}}\right)$} \\
\hline 20-29 Years & 0.80 & 0.50 & 0.72 & 1.27 & 1.11 & 0.78 & 0.48 & 0.47 & 0.46 \\
\hline 30-39 Years & 1.45 & 0.99 & 0.58 & 0.90 & 0.88 & 0.92 & 0.89 & 0.88 & 0.91 \\
\hline 40-49 Years & 0.27 & 0.33 & 0.28 & 2.17 & 1.32 & 0.21 & 0.19 & 0.24 & 0.20 \\
\hline \multicolumn{10}{|c|}{ Mother's education level (No education ${ }^{a}$ ) } \\
\hline Primary & 3.09 & 2.59 & 0.18 & 0.29 & 0.23 & 0.12 & 0.31 & 0.29 & 0.22 \\
\hline Secondary+ & 4.00 & 4.24 & 0.19 & 0.78 & 0.83 & 0.81 & 0.40 & 0.39 & 0.36 \\
\hline \multicolumn{10}{|c|}{ Marital Status of the mother (Never married/Separated ${ }^{\mathrm{a}}$ ) } \\
\hline Married/Cohabiting & 2.04 & 0.98 & 0.14 & 2.33 & 1.62 & 0.22 & 1.14 & 0.85 & 0.86 \\
\hline \multicolumn{10}{|c|}{ Mothers' occupation (Peasant ${ }^{a}$ ) } \\
\hline Pastoralist & 0.12 & 0.13 & $0.05^{*}$ & 2.53 & 2.39 & 0.33 & 2.11 & 2.61 & 0.55 \\
\hline Business/civil servant & 2.71 & 1.82 & 0.14 & 1.58 & 1.24 & 0.56 & 1.15 & 1.39 & 0.91 \\
\hline Handcraft & 1.23 & 1.74 & 0.92 & 0.24 & 0.27 & 0.21 & 1.15 & 1.38 & 0.90 \\
\hline
\end{tabular}

*Statistically significant at $95 \%$ Confidence Interval

${ }^{\text {a }}$ Reference category

(reference category) in Nakaseke and Nakasongola districts. In fact children aged 37-59 months and child underweight were statistically significant $\left(p=0.03^{* *}<0.05\right)$ at $95 \%$ confidence interval.

Findings also indicate that there is a significant relationship between woman's occupation and stunting among underfive children $(p=0.05)$ in Nakaseke and Nakasongola districts. Children whose mothers were pastoralists $(\mathrm{OR}=0.12)$ were less likely to be stunted unlike their counterparts whose mothers were peasant farmers (reference category) as shown in Table 5.

\section{Discussions}

\section{Conceptual frame work}

Figure 1 shows that in developing countries and particularly in Sub-Saharan Africa, under-five child malnutrition is normally determined by a large number of factors to the extent that it sometimes becomes difficult to predict the risk factors [8]. Such factors act through a number of interrelated proximate determinants to bring about underfive malnutrition that is stunting, underweight and wasting. The demographic and socio-economic factors such as age of child, birth order, mothers age at birth, mothers education level, marital status as well as maternal occupation work through proximate variables like the duration of breast feeding, sanitation and mothers health seeking behaviours to influence underfive malnutrition. With some modification, the UNICEF conceptual framework on nutrition strategy and child survival was adopted for this study [9]. Some of the variables in the UNICEF conceptual framework were not applicable to the study design adopted hence were not adopted in the paper for instance inadequate health facilities.

Study findings indicated a significant relationship between age of child and malnutrition. Children aged 37-59 months were found less likely to be underweight $(\mathrm{OR}=$ 0.76) than their counterparts who were aged 12 months 


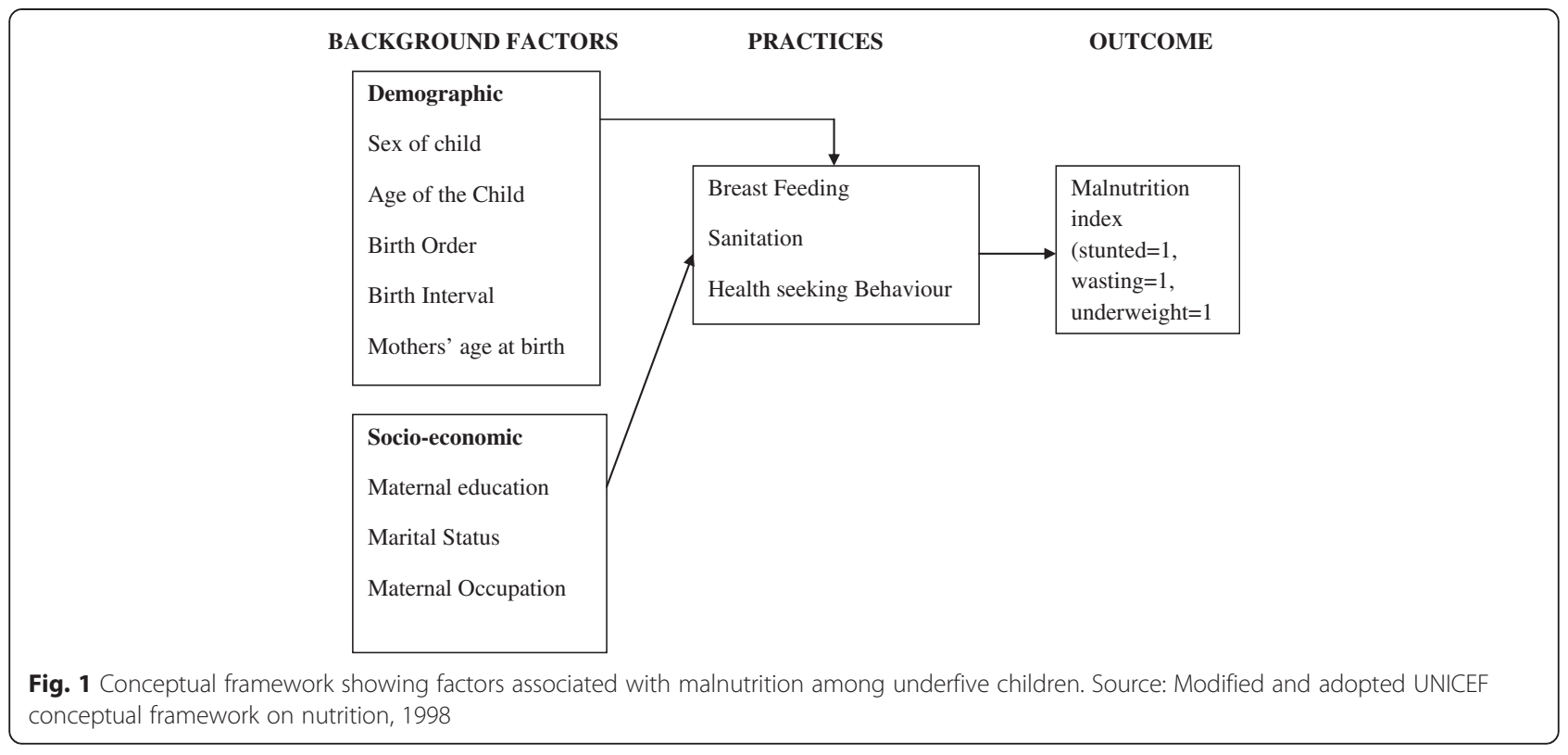

and below in the districts of Nakaseke and Nakasongola. Similar findings have been reported at national level where the proportion of underweight children is lowest among children 36-59 months old and highest among those 6-8 months old [3]. Other studies in Vietnam, India, Nigeria and Kenya have reported similar findings [10-12]. Perhaps, this could be associated with the fact that when children are weaned especially after exclusive breastfeeding in the first six months, some women go back to their work places and devote less time to the care of their children. The findings are however contrary to the study in Ethiopia that found out that underweight had a positive linear relationship with age of a child [13].

Furthermore, maternal occupation emerged as a significant factor that could be associated with underfive stunting in the same districts. Children from mothers who were pastoralists were found 0.12 times less likely to be stunted than children whose mothers were peasant farmers. Mothers engaged in pastoralism are believed to supplement the nutrition value of their children with cow milk and other milk products which consequently reduces the risk of stunting unlike the peasant farmers. According to a study in Botswana [14], crop cultivators were more likely to have stunted children. Similarly, a study done in Vietnam found out that children from mothers who were crop cultivators had an increased risk of stunting because they rarely get time to care for their children hence end up leaving them under the care of elder siblings or inexperienced maids [10]. In another study, by Olwedo, Mworozi and Bachou found some mothers particularly peasant farmers in most cases failed to provide complementary feeding to their children because they could not afford [15]. This factor therefore proposes that the economic engagement of the mother that particularly promote extended separation of the child from the primary caregiver may be detrimental consequently resulting into malnutrition especially stunting. However, observations from other studies suggest that women engagement in crop cultivation compared to informal businesses may be a reflective of the better resources and childcare practices within households particularly those with suitable childcare $[14,16,17]$. Worthy to note is that the above studies conducted elsewhere do not specifically compare children from peasant farmers with those from pastoralism communities on the stunting condition.

The present study reports on the level of malnutrition as well as the factors that could be associated with malnutrition among underfive children in Nakaseke and Nakasongola districts. Given that a substantial number of 104 underfive children were studied, the study may be regarded as a reasonable reflection of the nutritional status of underfive children in the above districts. Worthy to note also is that the study reveals that malnutrition is a problem that affects $38.5 \%$ (stunting), $16.5 \%$ (wasting) and $13.5 \%$ (underweight) of children underfive years in the two districts of Nakaseke and Nakasongola. The findings are slightly higher than the Uganda national figures of stunting at $33 \%$, and wasting at five percent. There is an almost similar proportion of underweight children with the national prevalence of $14 \%$ according to the 2011 Uganda Demographic and Health Survey [3]. Among the study limitations, the dataset used missed out some variables of interest on child malnutrition that included duration of breast feeding and Body Mass Index of the mother. The sample size of 104 respondents was also relatively small hence could have had an effect on the outcomes of the study. 


\section{Recommendations}

The study recommends exclusive breast feeding and proper complementary feeding especially among children under three years. In line with UNICEF and WHO recommendations, there is need for exclusive breast feeding during the first six months of life and thereafter semi-solid complementary foods are introduced up to at least two years or more. This will consequently reduce on the underweight children who are mostly aged less than three years in the districts of Nakaseke and Nakasongola.

The study also recommends a special arrangement for mothers engaged in cultivation to have their children breastfed regularly by having their babies brought to them in the gardens at regular intervals. The mothers could also visit their babies at home regularly from their gardens to ensure that proper nutrition is given to their children. This may contribute to a reduction in stunting especially among children of peasant farmers who were found to have increased levels of malnutrition than the rest of the children with mothers of other occupations.

There is need for a bigger study to be carried out in the districts of Nakaseke and Nakasongola covering more children to establish the factors associated with underfive malnutrition. Perhaps another study may establish significant factors like education of mother, sex of child, birth order, birth interval, age of mother and marital status since most of them were found significant in the literature review.

\section{Conclusion}

Results from the analyses confirm that age of a child and maternal occupation could be some of the factors associated with malnutrition among underfive children in Nakaseke and Nakasongola district. The study therefore underscores the age groups that could be prone to malnutrition challenges as well as the particular occupations among women that could pose a risk of malnutrition to the underfive children. This then could give a focus to policymakers in the designing of strategies aimed at combating malnutrition among children below five years. It should be noted however that some other factors could be associated with malnutrition among the underfive children and not necessarily the age of a child or even mothers occupation for instance, unemployed mother who breastfeeds her child could have a well fed child. Similarly, on the age of a child, it could be that the majority of the underweight children were just under a specific age group and not necessarily associated with malnutrition condition.

\section{Competing interests}

The author declares that he has no competing interests.

\section{Author's contributions}

HG conceived the study, performed data analyses, scientific content, interpretation of findings, discussion and conclusions. HG wrote and reviewed the manuscript. He also read and approved the final manuscript.

\section{Author's information}

HG is a senior researcher at Population and Development Consult Ltd, Kampala Uganda.

He has worked as a research fellow, Demographic and Social Statistics Section, United Nations Economic Commission for Africa (UNECA) in Addis Ababa, Ethiopia. HG graduated with Master of Science in Population Studies, Makerere University, Uganda.

\section{Acknowledgements}

I wish to extend my sincere thanks to my university supervisors; Associate Professor. L.K. Atuhaire and Dr Y.M. Lubaale for their invaluable guidance and support towards the execution of my Masters dissertation at Makerere University Uganda. Special gratitude is also extended to Allen Kabagenyi who proof read the article, made revisions and ensured that they were in line with the comments from the reviewers. Much appreciation also goes to the reviewers of my article for the job well done. I also extend my gratitude to Africa Innovations Institute that offered me one-year academic research scholarship as well as the data used for the study.

Received: 2 September 2014 Accepted: 11 September 2015

Published online: 24 September 2015

\section{References}

1. World Health Organization. Essential nutrition actions: Improving maternal, newborn, infant and young child health and nutrition. Geneva, Switzerland: WHO Document Publications Services; 2013.

2. Kimokoti RW, Hamer DH. Nutrition, health and aging in Sub-Saharan Africa. Nutr Rev. 2008:66 Suppl 11:611-23.

3. Uganda Bureau of Statistics (UBOS), ICF International Inc. Uganda Demographic and Health Survey 2011. Kampala, Uganda: UBOS and Calverton, Maryland: ICF International Inc; 2012.

4. MoH, MAAIF. Ministry of Health and Ministry of Agriculture, Animal Industry and Fisheries. Kampala, Uganda: The Uganda food and nutrition strategy; 2005.

5. Government of Uganda. A transformed Ugandan society from a Peasant to a Modern and Prosperous country within 30 years. Kampala, Uganda: Uganda Vision 2040 for the Republic of Uganda, National Planning Authority; 2013.

6. IDRC. Adaptation to the impact of climatic variability on food and health security in the cattle corridor of Uganda; Technical report by Africa Innovations Institute. Canada: Project funded by International Development Research Centre; 2013. Project fund number: 106039-001.

7. Gibson RS. Principles of nutritional Assessment. New York: Oxford University Press, Inc; 2005.

8. Victoria CG, Huttly SR, Fuchs SC, Olinto MT. The role of conceptual frameworks in epidemiological analysis: A hierarchical approach. Int J Epidemiol. 1997;26 Suppl 1:224-7.

9. UNICEF. The state of the World's children. Oxford: Oxford University Press; 1998.

10. Nguyen $\mathrm{NH}$, Kam S. Nutritional status and the characteristics related to malnutrition in children under-five years of age in Nghean, Vietnam. J Prev Med Public Health. 2008;41 Suppl 4:232-40.

11. Babatunde RO. Prevalence and determinants of malnutrition among underfive children of farming households in Kwara state, Nigeria [abstract]. J Agric Sci. 2011:3:s3.

12. Kabubo-Mariara J, Ndenge GK, Kirii DM. Determinants of Children's Nutritional Status in Kenya: Evidence from Demographic and Health Surveys. University of Oxford: Paper Presented at the Centre for the Study of African Economies Conference; 2006.

13. Yimer G. Malnutrition among children in southern Ethiopia: Levels and risk factors. Ethiop J Health Dev. 2000;14 Suppl 3:283-92.

14. Salah EO, Malgoub MN, Theopi TB. Factors affecting prevalence of malnutrition among children under three years of age in Botswana [abstract]. Afr J Food Agric Nutr Dev. 2006;6:s1.

15. Olwedo MA, Mworozi EM, Bachou H, Orach CG. Factors associated with malnutrition among children in internally displaced person's camps, Northern Uganda. Journal of Africa Health Sciences. 2008;8 Suppl 4:244-52.

16. Faruque ASG, Shamsir AMA, Tahmeed A, Munirul MI, labal MH, Roy SK, et al. Basis for healthy children and mothers in Bangladesh. Journal for health and population health. 2008:26 Suppl 3:325-39.

17. Gulati JK. Child Malnutrition: Trends and issues. Anthropologist. 2010;12 Suppl 2:131-40. 